\title{
BMJ Open Does time off work after injury vary by jurisdiction? A comparative study of eight Australian workers' compensation systems
}

\author{
Alex Collie, ${ }^{1,2}$ Tyler J Lane, ${ }^{1,2}$ Behrooz Hassani-Mahmooei, ${ }^{1}$ Jason Thompson, ${ }^{1}$ \\ Chris McLeod ${ }^{3}$
}

To cite: Collie A, Lane TJ, Hassani-Mahmooei B, et al. Does time off work after injury vary by jurisdiction? A comparative study of eight Australian workers' compensation systems. BMJ Open 2016;6:e010910. doi:10.1136/bmjopen-2015010910

- Prepublication history and additional material is available. To view please visit the journal (http://dx.doi.org/ 10.1136/bmjopen-2015010910).

Received 20 December 2015 Revised 4 April 2016 Accepted 11 April 2016

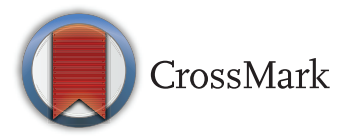

${ }^{1}$ Institute for Safety, Compensation and Recovery Research, Monash University, Melbourne, Victoria, Australia ${ }^{2}$ School of Public Health and Preventive Medicine, Monash University, Melbourne, Victoria, Australia

${ }^{3}$ Partnership for Work, Health and Safety, University of British Columbia, Vancouver, British Columbia, Canada

Correspondence to Dr Alex Collie; alex.collie@ monash.edu

\section{ABSTRACT}

Objectives: To determine whether the jurisdiction in which a work-related injury compensation claim is made is an independent predictor of duration of time off work following work injury, and if so, the magnitude of the effect.

Setting: Eight Australian state and territory workers' compensation systems, providing coverage for more than $90 \%$ of the Australian labour force. Administrative claims data from these systems were provided by government regulatory authorities for the study.

Participants: 95976 Australian workers with workers' compensation claims accepted in 2010 and with at least 2 weeks of compensated time off work.

Primary outcome measure: Duration of time lost from work in weeks, censored at 104 weeks.

Results: After controlling for demographic, worker, injury and employer factors in a Cox regression model, significant differences in duration of time loss between state and territory of claim were observed. Compared with New South Wales, workers in Victoria, South Australia and Comcare had significantly longer durations of time off work and were more likely to be receiving income benefits at 104 weeks postinjury, while workers in Tasmania and Queensland had significantly shorter durations of time off work.

Conclusions: The jurisdiction in which an injured worker makes a compensation claim has a significant and independent impact on duration of time loss. Further research is necessary to identify specific compensation system policies and practices that promote timely and appropriate return to work and reduce duration of time off work.

\section{INTRODUCTION}

There are an estimated 4.8 million deaths from injury annually, accounting for over $10 \%$ of the total global burden of disease, with 973 million people sustaining injury that resulted in access to healthcare. ${ }^{1}$ In the sphere of work injury, the International Labour Organisation ${ }^{2}$ has estimated that

\section{Strengths and limitations of this study}

- Use of population-based data from 8 of the 10 Australian workers' compensation jurisdictions, covering more than $90 \%$ of the Australian labour force.

- Ability to account for factors, other than jurisdiction of claim, that are known to impact on return to work outcomes, including age, gender, occupation, injury type and socioeconomic status.

- Use of income replacement duration as a proxy for return to work outcomes produces some uncertainty in estimates.

there are 2.3 million fatalities and a further 313 million injuries arising from work-related accidents annually. These figures underestimate the true burden of work-related injury and illness as they exclude the substantial additional burden of occupational diseases and work-related mental health conditions.

Work injury results in changes to physical and mental health, quality of life and a reduced ability to participate in society and the labour market. ${ }^{3-5}$ Extended periods of worklessness can have a negative impact on health. ${ }^{5}$ Work injury may have flow on effects such as increasing the risk of marital separation $^{6}$ and has been associated with poorer health of family members. ${ }^{7}$

Most industrialised and developing nations have public insurance systems that compensate injured workers for periods of time away from work and seek to promote effective rehabilitation and return to work (RTW). ${ }^{8}$ There is substantial international variation in the design and management of these systems. ${ }^{9}$ Differences between jurisdictions include the proportion of the labour market covered, caps and time period limits on wage replacement, access to treatment and rehabilitation and time limits on benefit 
periods, among others. ${ }^{10}$ This diversity in system design and policy presents an opportunity for comparative research to identify the most effective policy settings for minimising duration of work disability.

Prior research has established the association between RTW outcome and a range of biological/physical, psychological, social and demographic factors. These include worker characteristics including age ${ }^{11}$ and gender, ${ }^{12}$ injury characteristics including type of injury, ${ }^{13}$ workplace-level factors ${ }^{14}$ and psychological factors including self-efficacy ${ }^{15}$ and pain catastrophising. ${ }^{16}$ Globally, very little quality evidence regarding the relative impact of compensation system policy on duration of work disability has been published. ${ }^{17}$ One study examining RTW outcomes in cohorts of workers with lower back pain from six countries identified that access to long-term disability benefits and the degree of impairment required to access such benefits were independently associated with the sustainability of RTW. ${ }^{17}$ Another study across 49 states of the USA identified that waiting periods for wage replacement and policies around access to medical treatment were independently associated with duration of disability in workers with lower back pain. ${ }^{18}$ However, a systematic review identified that many studies of health and recovery outcomes in those with compensable injury fail to report even basic characteristics of the compensation system. ${ }^{9}$

In Australia, more than half a million workers were injured at work in the 2013/2014 financial year, ${ }^{19}$ equating to $4.3 \%$ of the labour force. The societal cost of work injury has been estimated at $\$ 60.6$ billion per annum, or $4.8 \%$ of gross domestic product (GDP). ${ }^{20}$ Commonwealth and state governments in Australia have established an array of workers' compensation systems with the objective of returning injured workers to the workforce while minimising the costs of rehabilitation to society. ${ }^{10}$ These are predominantly geographically based in the six states and two territories. In addition, there are two commonwealth workers' compensation systems. ${ }^{10}$ All of these compensation schemes provide income replacement, healthcare and rehabilitation support to eligible injured workers. Among the Australian systems, there is a diversity of policy approaches. The schemes differ on multiple aspects including their coverage (eg, industries and workers covered); entitlements (eg, included injuries and illnesses); benefits (eg, minimum and maximum levels and duration); rehabilitation (eg, early RTW, access to support); healthcare (eg, access to and coverage); administration (eg, appeal procedures, oversight mechanisms); financing (eg, who pays, experience rating) and job protection (eg, duration of protection, employer obligation to accommodate injured worker). ${ }^{10}$ These are all factors that have been identified as important to fairness of coverage and outcomes for injured workers, ${ }^{21}$ and provide an opportunity to study the relative impact of different policy approaches on outcomes including RTW.
This study is the first in a planned series of analyses of a newly established national research data set of workers' compensation outcomes. The objective of this study is to determine whether the Australian state or territory in which an injured worker makes their compensation claim is an independent predictor of the duration of time off work, and if so, to determine the magnitude of this effect. Should a significant and independent effect of jurisdiction be observed, subsequent analyses will examine the contribution of specific policy settings to duration of work disability.

\section{METHODS}

\section{Setting}

In December 2010, the year of focus for this study, Australia had a labour force of 11.42 million workers. The vast majority of Australian workers are covered by compulsory workers' compensation insurance regulated by state, territory and commonwealth government authorities. A total of 8 of the 10 major Australian compensation systems are included in this study, including the states of New South Wales, Victoria, Queensland, Western Australia, South Australia, Tasmania and the Northern Territory. In addition, the Comcare scheme covering commonwealth government employees, government employees of the Australian Capital Territory (ACT) and more than 30 large national firms was included. Claims arising from private sector organisations in the ACT were incomplete; claims from Seacare were too few to include; and claims data from the military were not available.

The systems share many common features. They provide coverage for employees of working age within the relevant jurisdiction. Many common work-related physical conditions are eligible for compensation, including acute traumatic injuries and chronic or gradual onset conditions (eg, chronic lower back pain). Most jurisdictions also accept 'psychological injury' or mental health claims, and some diseases, where there is a demonstrable link between the condition and the workplace. Benefits provided by the compensation systems typically include healthcare expenses and income replacement payments to injured workers for the period of time they are off work. The Australian systems often also pay costs associated with occupational or vocational rehabilitation and retraining. Some injured workers with a permanent injury or disability may also be eligible to receive lump-sum payments. Healthcare and other medical expenses are typically provided on the basis that they are 'reasonable and necessary' as determined by the claims management organisation. Income replacement payments are usually capped at a percentage of the workers' preinjury earnings.

The process of making a workers' compensation claim is largely consistent between jurisdictions. Workers who have incurred an injury at work and are intending to 
make a workers' compensation claim must provide their employer, and in some cases their insurer, with information about their injury. This information, captured on a 'claim form', must be accompanied by a medical certificate from a general practitioner or other qualified medical practitioner. The employer must then notify the claims management organisation of the claim within a specified time, and the claims management organisation usually has a period of time to determine whether the claim is eligible for workers' compensation benefits under the legislation, and to accept or deny the claim.

Despite their similarities, there are also many areas in which Australian workers' compensation jurisdiction varies in policy and practice. A detailed description of these is out of scope for this study; however, it is useful to identify some of the major structural and functional differences as context to the study. There are differences relating to the waiting period for access to compensation. Victoria and South Australia each have a 10-day waiting period during which the employer is required to provide income replacement. The other states and territories have waiting period of 0 or 1 day. The relationship of claims management or insurance function to the regulation function also differs. Comcare is the government regulator and claims manager. Queensland has a single major insurer for the majority of claims that is separate from the system regulator. South Australia has two private sector insurers that manage claims on behalf of the state regulator. Victoria has five private sector insurers managing claims that are separate from the regulator. There are differences relating to the rate and duration of income replacement. Most jurisdictions provide $100 \%$ of preinjury average weekly earnings (PIAWE) during the first 3-6 months of time loss, while Queensland covers $85 \%$ for the first 6 months, and New South Wales and Victoria cover $95 \%$ for 3 months before dropping to $80 \%$. The Victorian scheme caps the duration of income replacement at 130 weeks, whereas there are longer periods in the other states. Under the Comcare scheme, income benefits may be payable until the worker reaches the national retirement age of 65 . These types of policy settings change routinely within jurisdictions. In 2012, there were some major structural reforms to the New South Wales workers' compensation system that restricted access to compensation and benefits. In 2015, the South Australian government introduced new workers' compensation legislation that radically changed the design of that state's system. A detailed description of the policy settings and changes within jurisdictions is published annually by Safe Work Australia. ${ }^{10}$

\section{Data sources}

Annually, the Australian workers' compensation authorities contribute case-level claims data to the National Data Set for Compensation-based Statistics (NDS), compiled by Safe Work Australia. ${ }^{22}$ A total of 305774 cases of compensated work injury occurring in the 2010 calendar year were extracted from the NDS.

Cases were excluded if the worker was aged $<15$ years or $>80$ years $(\mathrm{n}=20$ excluded) and if the NDS indicated they had worked $<1$ or $>100 \mathrm{~h}$ per week prior to injury $(n=63225)$. Cases arising from the ACT private systems were removed due to that jurisdiction not reporting postcode data necessary for calculation of some predictors $(\mathrm{n}=4669)$. To ensure comparable jurisdictional-level cohorts were established, cases with 2 weeks or less time loss were removed to account for jurisdictional variation in compensation system criterion for claim acceptance (Victoria and South Australia have employer excess periods of 2 weeks, during which employers typically cover income replacement payments; $n=141615$ ). Finally, a number of duplicate cases were also removed $(n=39)$. Following application of inclusion and exclusion criteria, a total of 95976 cases remained for analyses.

\section{Outcome variables}

The primary outcome was duration of time lost, measured as the cumulative number of weeks compensation paid. Cumulative duration is considered an appropriate estimate of time off work when using administrative data. ${ }^{23}$ Duration was calculated by dividing the number of hours compensated by the number of preinjury work hours per week to produce the number of compensated weeks. The data set included claims information to June 2014, providing a maximum 4.5-year period of follow-up. For each case in the data set, duration was censored at a maximum of 104 weeks of time loss, consistent with our prior analyses on similar data sets. ${ }^{124}$

\section{Independent variables}

Factors previously associated with duration of work disability including age, gender, occupation, industry, socioeconomic status (SES), remoteness and injury type were derived from the NDS data set for inclusion in the analyses. Age refers to worker's age at the time of injury/ disease onset. Occupation was classified into nine occupation group codes using the Australian and New Zealand Standard Classification of Occupations (ANZSCO) ${ }^{25}$ Industry was classified according to the Australian and New Zealand Standard Industrial Classification (ANZSIC). ${ }^{26}$

Nature of injury was classified using a modification of the Type of Occurrence Classification System (TOOCS), V.3. ${ }^{27}$ Quality assurance analyses of the data set identified inconsistencies between jurisdictions in application of TOOCS coding, creating discrepancies in some categories, particularly musculoskeletal injuries and trauma. These could not be fully attributed to regional variations in injury type and likely reflected variations in coding practices that could not be controlled statistically. To account for this issue, a modified injury coding system was developed that collapsed chronic and traumatic musculoskeletal injuries into a single category. 
Categories related to fractures, mental health conditions and diseases were retained.

Postcode was linked to the Accessibility/Remoteness Index of Australia (ARIA), ${ }^{28}{ }^{29}$ an indicator of remoteness, and the Index of Relative Socio-Economic Advantage and Disadvantage (IRSAD), ${ }^{30}$ an indicator of SES. ARIA classifies postcodes into five categories: major cities, inner regional, outer regional, remote and very remote. IRSAD classifies postcodes into ranked deciles of relative socioeconomic advantage or disadvantage. Claimants were assigned an ARIA classification and IRSAD decile score given to the postcode in which they lived. The highest and lowest ranking two IRSAD deciles were grouped into 'advantaged' and 'disadvantaged' SES quintiles for analyses. Claimants who worked 35 or more hours work per week preinjury were classified as full time.

Jurisdiction was the final predictor and was categorised as the compensation system in which the claim was accepted. As described above, these are typically organised geographically according to state or territory of injury, with the exception of the Comcare scheme which has national coverage of employees of the federal government and $\sim 35$ large national corporations.

\section{Analysis}

Injured worker characteristics and median duration of time loss in weeks were summarised nationally and for each jurisdiction. Predictor variables were tested for association with the outcome variable (duration of time loss) in univariate Cox regression. Non-parametric tests (Kruskal-Wallis for categorical (dichotomous), Mann-Whitney for categorical ( $>2$ categories) and Spearman rank (ordered categorical)) were used to assess associations.

Predictors that were significantly associated with duration of time loss were included in a stepwise Cox regression model. All predictor variables, with the exception of jurisdiction, were entered into the model in the first step. Jurisdiction was added in the second step to determine whether it added any explanatory power to the model, and how it affected associations with other predictor variables. Cases exceeding 104 weeks of time loss were right censored. Outputs are reported as adjusted HR with $99 \%$ CI.

Duration of time loss was plotted in a survival curve to illustrate the proportion of injured workers receiving compensation over time and differences by jurisdiction. The survival curve is derived from the Cox regression and controls for covariates. A high proportion (13.7\%) of values derived from postcode data (IRSAD (advantage/disadvantage) and ARIA (remoteness)) were missing. Values were imputed using fully conditional specification multiple imputation (five imputations) on the assumption that they were missing at random (MAR). This model is compared with a complete case regression. Data manipulations and analyses were conducted using SPSS V.22, with $p$ values of $\leq 0.01$ considered significant.

\section{Ethics}

This study received ethics approval from the Monash University Human Research Ethics Committee (MUHREC) on 8 October 2014.

\section{RESULTS}

\section{Participant characteristics}

Participant characteristics are presented in table 1 . Western Australia $(33.1 \%)$ and the Northern Territory $(30.8 \%)$ had a smaller proportion of injured female workers than the national average $(37.6 \%)$, while Comcare was much higher at $44.6 \%$. Non-fracture physical health injuries were similarly common at around three-quarters of claimants in each, though the distribution of mental health claims varied substantially; Comcare (14.6\%), Tasmania (11.5\%) and Victoria (10.2\%) had the highest proportion of claims for mental health conditions, while Western Australia had the lowest $(3.3 \%)$. Manufacturing was the most common employer industry in Victoria (18.8\%), and public administration and safety in the Northern Territory $(12.0 \%)$. Healthcare and social assistance was the most common industry overall $(15.3 \%)$. While labourers were the most common occupation nationally (22.9\%) and in most jurisdictions, clerical and administrative workers were most common in Comcare (50.9\%). Socioeconomically advantaged postcodes were overrepresented in Comcare $(38.8 \%)$ and Western Australia $(30.2 \%)$, while disadvantaged postcodes were overrepresented in South Australia (30.1\%) and Tasmania $(49.0 \%)$.

\section{Duration of compensated time loss}

Table 2 presents summary statistics on duration of time loss between jurisdictions. Median time loss across the entire sample was 9.2 weeks (IQR: 4.2-26.6). Victoria (13.2 weeks) and South Australia (10.0 weeks) had the longest median durations, while Tasmania (7.1 weeks) and Queensland (7.8 weeks) had the shortest. Differences were also reflected in the proportion of claims that received at least 2 years' compensated time loss: $14.0 \%$ of cases in South Australia and $16.0 \%$ in Victoria received at least 104 weeks' compensated time loss, compared with $1.0 \%$ of accepted claims in Queensland.

\section{Cox regression analysis}

In univariate analyses, all independent variables were significantly associated with the outcome variable at the $\mathrm{p}<0.01$ level, and as such were entered into the multivariate model. Cox regression models included 95655 cases, $8109(8.5 \%)$ of which were censored for having time-loss durations that exceeded 104 weeks. Values were missing for $13.7 \%$ of advantage/disadvantage 
Table 1 Injured worker characteristics by jurisdiction of compensation claim

\begin{tabular}{|c|c|c|c|c|c|c|c|c|c|}
\hline & $\begin{array}{l}2010 / 2011 \\
\text { covered } \\
\text { workers } \\
\text { (thousands)* }^{*}\end{array}$ & $\begin{array}{l}\text { Workers (>2 } \\
\text { weeks' time } \\
\text { loss) }\end{array}$ & $\begin{array}{l}\text { Mean (SD) } \\
\text { age in } \\
\text { years }\end{array}$ & $\begin{array}{l}\text { Female \% } \\
\text { (n) }\end{array}$ & $\begin{array}{l}\text { Mental health } \\
\text { condition, } \\
\%(n)\end{array}$ & $\begin{array}{l}\text { Most common } \\
\text { industry, \% (n) }\end{array}$ & $\begin{array}{l}\text { Most common } \\
\text { occupation, } \\
\% \text { (n) }\end{array}$ & $\begin{array}{l}\text { Most } \\
\text { advantaged } \\
\text { quintile, \% (n) }\end{array}$ & $\begin{array}{l}\text { Most } \\
\text { dis-advantaged } \\
\text { quintile, \% (n) }\end{array}$ \\
\hline Entire data set & 10096 & 95976 & $42.2(12.6)$ & $37.6(36$ 134) & 7.7 (7349) & $\begin{array}{l}\mathrm{HC} / \mathrm{SA} \\
15.3(14 \text { 491) }\end{array}$ & $\begin{array}{l}\text { Labourers } \\
22.9 \text { (21 973) }\end{array}$ & 18.5 (15 347) & 17.9 (14 799) \\
\hline New South Wales & 3078 & 33399 & $42.1(12.6)$ & $38.2(12767)$ & 8.1 (2709) & $\begin{array}{l}\mathrm{HC} / \mathrm{SA} \\
14.7(4896)\end{array}$ & $\begin{array}{l}\text { Labourers } \\
20.2(6756)\end{array}$ & $21.2(5477)$ & 19.9 (5139) \\
\hline Victoria & 2577 & 18965 & $43.2(12.4)$ & 36.8 (6973) & $10.2(1930)$ & $\begin{array}{l}\text { Manufacturing } \\
18.8(3573)\end{array}$ & $\begin{array}{l}\text { Labourers } \\
23.8 \text { (4522) }\end{array}$ & $18.4(3126)$ & 15.7 (2674) \\
\hline Queensland & 1900 & 21722 & $41.3(12.8)$ & $37.6(8171)$ & 4.8 (1032) & $\begin{array}{l}\mathrm{HC} / \mathrm{SA} \\
15.8 \text { (3406) }\end{array}$ & $\begin{array}{l}\text { Labourers } \\
27.4 \text { (5910) }\end{array}$ & $12.8(2787)$ & 16.6 (3605) \\
\hline South Australia & 719 & 6402 & $42.8(12.1)$ & $41.6(2665)$ & $9.6(616)$ & $\begin{array}{l}\mathrm{HC} / \mathrm{SA} \\
24.0(1378)\end{array}$ & $\begin{array}{l}\text { Labourers } \\
21.4 \text { (1371) }\end{array}$ & $9.3(455)$ & 30.1 (1466) \\
\hline Western Australia & 1098 & 9195 & $41.7(13.0)$ & 33.1 (3042) & $3.3(308)$ & $\begin{array}{l}\mathrm{HC} / \mathrm{SA} \\
15.8(1448)\end{array}$ & $\begin{array}{l}\text { Labourers } \\
24.5 \text { (2257) }\end{array}$ & $30.2(2186)$ & $4.0(290)$ \\
\hline Tasmania & 210 & 2491 & $42.0(12.3)$ & 38.9 (969) & $11.5(286)$ & $\begin{array}{l}\mathrm{HC} / \mathrm{SA} \\
17.9(445)\end{array}$ & $\begin{array}{l}\text { Labourers } \\
31.8(793)\end{array}$ & $3.3(83)$ & $49.0(1218)$ \\
\hline Northern Territory & 114 & 1068 & $40.5(13.3)$ & 30.8 (329) & $6.4(68)$ & $\begin{array}{l}\text { Public } \\
\text { administration } \\
\text { and safety } \\
12.0(128)\end{array}$ & $\begin{array}{l}\text { Labourers } \\
23.2(248)\end{array}$ & 18.5 (177) & $15.4(147)$ \\
\hline Comcare & 400 & 2734 & $46.0(10.1)$ & 44.6 (1218) & $14.6(400)$ & $\begin{array}{l}\mathrm{HC} / \mathrm{SA} \\
15.3(1557)\end{array}$ & $\begin{array}{l}\text { Clerical and } \\
\text { administrative } \\
50.9(1392)\end{array}$ & $38.8(1056)$ & $9.5(260)$ \\
\hline
\end{tabular}


Table 2 Duration of compensated time loss by jurisdiction

\begin{tabular}{|c|c|c|c|c|}
\hline \multirow[b]{2}{*}{ Jurisdiction } & \multirow{2}{*}{$\begin{array}{l}\mathrm{N}(\mathrm{col} \%) \text { workers } \\
\text { included }\end{array}$} & \multicolumn{2}{|c|}{ Weeks' time loss } & \multirow{2}{*}{$\begin{array}{l}\mathrm{N}(\text { row } \%) \text { off work } \\
\text { at } 104 \text { weeks }\end{array}$} \\
\hline & & Median & IQR & \\
\hline Total & 95976 (100) & 9.2 & $(4.2-26.6)$ & $8127(8.5)$ \\
\hline New South Wales & 33399 (34.8) & 8.5 & (3.9-26.6) & $3189(9.5)$ \\
\hline Victoria & $18965(19.8)$ & 13.2 & $(5.6-51.6)$ & $3028(16.0)$ \\
\hline Queensland & 21722 (22.6) & 7.8 & $(4.0-17.6)$ & $223(1.0)$ \\
\hline South Australia & $6402(6.7)$ & 10.0 & $(4.6-39.3)$ & $894(14.0)$ \\
\hline Western Australia & 9915 (10.3) & 9.8 & $(4.2-29.0)$ & $402(4.4)$ \\
\hline Tasmania & 2491 (2.6) & 7.1 & (3.8-16.3) & $123(4.9)$ \\
\hline Northern Territory & $1068(1.1)$ & 9.0 & $(4.4-22.2)$ & $36(3.4)$ \\
\hline Comcare & $2734(2.8)$ & 8.9 & $(4.1-26.4)$ & $232(8.5)$ \\
\hline
\end{tabular}

( $n=13$ 189) and remoteness variables $(n=13164)$ due to missing, invalid and unmatched postcode data. Values were assigned using multiple imputation. Higher HRs indicate greater likelihood of leaving the compensation system at any point and thus shorter durations of time loss. Results of the final Cox proportional hazards model are reported in table 3 .

In the final model, female workers (HR: 0.89; CI (99\%) 0.87 to 0.91 ) had significantly longer duration than male workers. Compared with injured workers from the middle six IRSAD deciles, those from the most disadvantaged areas had significantly longer durations (HR: 0.95; CI (99\%) 0.92 to 0.98$)$, while those from the most advantaged areas had significantly shorter durations (HR: 1.09; CI (99\%) 1.06 to 1.12). The age of the worker displayed a graded relationship with duration of time loss; compared with the reference group aged 2534 years, the youngest group (15-24 years) had significantly shorter durations (HR: 1.30; CI (99\%) 1.26 to 1.34), while older groups had longer durations (HR: 0.82 to 0.85 ; all $\mathrm{p}<0.001)$. Remoteness was significantly associated with shorter durations in the model excluding jurisdiction. In the final model, remoteness was no longer significant ( $p$ value range: $0.063-0.123$ ), indicating that associations between greater remoteness and duration of time loss are not independent of jurisdiction.

Workers from manual labour industries, including agriculture, forestry, fishing, manufacturing (HR: 0.78; CI $(99 \%) 0.73$ to 0.83 ), mining (HR: 0.76; CI $(99 \%)$ 0.71 to 0.82 ) and construction (HR: 0.74; CI (99\%) 0.71 to 0.77 ) had longer durations when compared with the most common industry of healthcare and social assistance. Managers (HR: 1.06; CI (99\%) 1.02 to 1.12 ), professionals (HR: 1.09; CI (99\%) 1.05 to 1.13), technicians and trade workers (HR: 1.07; CI (99\%) 1.04 to 1.11 ), and clerical/administrative workers (HR: 1.09; CI $(99 \%)$ 1.04 to 1.13 ) experienced shorter durations of time loss than the comparison group of labourers. Full-time workers had shorter time-loss durations (HR: 1.06; CI (99\%) 1.04 to 1.09$)$. Notably, this effect was a reversal from what was observed in the complete case models (see online supplementary table and impact of missing data below).
Using physical injury (excluding fractures) as the comparator, workers with mental health conditions had significantly longer durations of time loss (HR: 0.63; CI (99\%) 0.61 to 0.65 ), while workers with diseases had significantly shorter durations (HR: 1.35; CI (99\%) 1.30 to 1.40).

Adjusting for covariates and using New South Wales as the reference category, workers in Victoria (HR: 0.75; CI (99\%) 0.73 to 0.77 ), South Australia (HR: 0.84; CI (99\%) 0.81 to 0.88 ) and Comcare (HR: 0.91; CI $(99 \%)$ 0.85 to 0.96 ) had significantly longer durations. Injured workers in Queensland (HR: 1.32; CI (99\%) 1.29 to 1.36) and Tasmania (HR: 1.31 ; CI (99\%) 1.24 to 1.39$)$ had significantly shorter durations than workers in New South Wales. Northern Territory approached significance $(\mathrm{p}=0.012)$ as having shorter duration (HR: 1.09; CI $(99 \%) 1.00$ to 1.20$)$.

Adjusted survival estimates (figure 1) illustrate the variation in time-loss durations between jurisdictions, after accounting for other factors that are associated with duration. Workers in Victoria had the highest probability of receiving time-loss benefits (being off work) throughout the 104-week follow-up period, followed by workers from South Australia and Comcare. Workers in Tasmania and Queensland had the lowest probability, their curves practically overlapping. The remaining three jurisdictions of New South Wales, Western Australia and the Northern Territory are clustered with similar survival trajectories. The differences between jurisdictions are marked. The cumulative probability of survival at 20 weeks is $\sim 0.5$ in Victoria, whereas in Tasmania and Queensland, the probability at this time point is approximately half that at 0.2 . These differences persist throughout the 104-week follow-up period.

\section{Impact of missing data}

Missing values for SES advantage/disadvantage and remoteness variables were multiply imputed under the assumption they were MAR (not independent of variables outside the model). For comparison, complete case Cox regression outputs are presented in the online supplementary table. 
Table 3 Factors associated with duration of time loss (weeks), Cox regression with multiple imputation for advantage/ disadvantage and remoteness

\begin{tabular}{|c|c|c|c|c|c|c|}
\hline \multirow[b]{2}{*}{ Variables in equation } & \multicolumn{3}{|c|}{ Model 1} & \multicolumn{3}{|c|}{ Model 2} \\
\hline & HR & $(99 \% \mathrm{Cl})$ & p Value & HR & $(99 \% \mathrm{Cl})$ & p Value \\
\hline \multicolumn{7}{|l|}{ Jurisdiction (reference: New South Wales) } \\
\hline Victoria & & & & 0.75 & (0.73 to 0.77 ) & $<0.001$ \\
\hline Queensland & & & & 1.32 & (1.29 to 1.36$)$ & $<0.001$ \\
\hline South Australia & & & & 0.84 & (0.81 to 0.88 ) & $<0.001$ \\
\hline Western Australia & & & & 0.99 & (0.96 to 1.02$)$ & 0.492 \\
\hline Tasmania & & & & 1.31 & (1.24 to 1.39 ) & $<0.001$ \\
\hline Northern Territory & & & & 1.09 & (1.00 to 1.19$)$ & 0.012 \\
\hline Commonwealth Comcare & & & & 0.91 & (0.85 to 0.96$)$ & $<0.001$ \\
\hline \multicolumn{7}{|l|}{ Gender (reference: male) } \\
\hline Female & 0.89 & (0.87 to 0.91$)$ & $<0.001$ & 0.89 & (0.87 to 0.91$)$ & $<0.001$ \\
\hline \multicolumn{7}{|l|}{ Age (reference: $26-35$ years) } \\
\hline $15-24$ years & 1.30 & (1.26 to 1.35$)$ & $<0.001$ & 1.30 & (1.26 to 1.34$)$ & $<0.001$ \\
\hline $35-44$ years & 0.85 & (0.83 to 0.88$)$ & $<0.001$ & 0.85 & (0.83 to 0.88$)$ & $<0.001$ \\
\hline $45-54$ years & 0.82 & (0.80 to 0.84$)$ & $<0.001$ & 0.83 & (0.81 to 0.85$)$ & $<0.001$ \\
\hline 55 years and over & 0.80 & (0.78 to 0.83$)$ & $<0.001$ & 0.82 & (0.79 to 0.84$)$ & $<0.001$ \\
\hline \multicolumn{7}{|c|}{ Advantage/disadvantage (reference: middle three quintiles) } \\
\hline Most disadvantaged quintile & 0.95 & $(0.92$ to 0.97$)$ & $<0.001$ & 0.95 & (0.92 to 0.98$)$ & $<0.001$ \\
\hline Most advantaged quintile & 1.07 & (1.05 to 1.10$)$ & $<0.001$ & 1.09 & (1.06 to 1.12$)$ & $<0.001$ \\
\hline \multicolumn{7}{|l|}{ Remoteness (reference: major city) } \\
\hline Inner regional & 1.04 & (1.02 to 1.07$)$ & $<0.001$ & 1.02 & (0.99 to 1.04$)$ & 0.063 \\
\hline Outer regional & 1.10 & (1.06 to 1.14$)$ & $<0.001$ & 1.02 & (0.99 to 1.06$)$ & 0.076 \\
\hline Remote & 1.08 & (1.01 to 1.16$)$ & .004 & 1.05 & (0.97 to 1.12$)$ & 0.118 \\
\hline Very remote & 1.18 & (1.06 to 1.32$)$ & $<0.001$ & 1.07 & (0.96 to 1.20$)$ & 0.123 \\
\hline \multicolumn{7}{|l|}{ Part-time/full-time hours (reference: part time) } \\
\hline Full time & 1.06 & (1.04 to 1.09$)$ & $<0.001$ & 1.06 & (1.04 to 1.09$)$ & $<0.001$ \\
\hline \multicolumn{7}{|c|}{ Employer industry (reference: healthcare and social assistance) } \\
\hline Agriculture, forestry and fishing & 0.80 & $(0.75$ to 0.85$)$ & $<0.001$ & 0.78 & $(0.73$ to 0.83$)$ & $<0.001$ \\
\hline Mining & 0.79 & (0.74 to 0.85$)$ & $<0.001$ & 0.76 & (0.71 to 0.82$)$ & $<0.001$ \\
\hline Manufacturing & 0.83 & (0.80 to 0.86$)$ & $<0.001$ & 0.84 & (0.81 to 0.88$)$ & $<0.001$ \\
\hline Electricity, gas, water and waste services & 0.95 & (0.86 to 1.05$)$ & .184 & 0.92 & (0.83 to 1.01$)$ & 0.024 \\
\hline Construction & 0.75 & (0.72 to 0.78$)$ & $<0.001$ & 0.74 & (0.71 to 0.77$)$ & $<0.001$ \\
\hline Wholesale trade & 0.77 & (0.73 to 0.81$)$ & $<0.001$ & 0.79 & (0.75 to 0.83 ) & $<0.001$ \\
\hline Retail trade & 0.78 & (0.74 to 0.82$)$ & $<0.001$ & 0.78 & (0.74 to 0.82$)$ & $<0.001$ \\
\hline Accommodation and food services & 0.90 & (0.85 to 0.94$)$ & $<0.001$ & 0.85 & (0.81 to 0.90$)$ & $<0.001$ \\
\hline Transport, postal and warehousing & 0.83 & (0.79 to 0.87$)$ & $<0.001$ & 0.84 & (0.80 to 0.88$)$ & $<0.001$ \\
\hline Information media and telecommunications & 0.82 & (0.72 to 0.93$)$ & $<0.001$ & 0.81 & (0.71 to 0.92$)$ & $<0.001$ \\
\hline Financial and insurance services & 0.86 & (0.79 to 0.94$)$ & $<0.001$ & 0.85 & (0.78 to 0.94$)$ & $<0.001$ \\
\hline Rental, hiring and real estate services & 0.88 & (0.81 to 0.96$)$ & $<0.001$ & 0.88 & (0.80 to 0.96$)$ & $<0.001$ \\
\hline Professional, scientific and tech services & 0.86 & (0.81 to 0.92$)$ & $<0.001$ & 0.85 & (0.79 to 0.91$)$ & $<0.001$ \\
\hline Administrative and support services & 0.84 & (0.80 to 0.88$)$ & $<0.001$ & 0.80 & (0.76 to 0.84$)$ & $<0.001$ \\
\hline Public administration and safety & 0.93 & (0.89 to 0.96$)$ & $<0.001$ & 0.90 & (0.87 to 0.94$)$ & $<0.001$ \\
\hline Education and training & 1.10 & (1.06 to 1.15$)$ & $<0.001$ & 1.06 & (1.01 to 1.11$)$ & 0.001 \\
\hline Arts and recreation services & 0.80 & (0.74 to 0.86$)$ & $<0.001$ & 0.85 & (0.79 to 0.92$)$ & $<0.001$ \\
\hline Other services & 0.83 & (0.78 to 0.88$)$ & $<0.001$ & 0.81 & (0.77 to 0.86$)$ & $<0.001$ \\
\hline \multicolumn{7}{|l|}{ Occupation (reference: labourers) } \\
\hline Managers & 1.03 & (0.98 to 1.07$)$ & 0.177 & 1.06 & (1.02 to 1.12$)$ & 0.001 \\
\hline Professionals & 1.07 & (1.03 to 1.11$)$ & $<0.001$ & 1.09 & (1.05 to 1.13$)$ & $<0.001$ \\
\hline Technicians and trades workers & 1.06 & (1.03 to 1.09$)$ & $<0.001$ & 1.07 & (1.04 to 1.11$)$ & $<0.001$ \\
\hline Community and personal service workers & 1.02 & (0.98 to 1.05$)$ & 0.244 & 1.02 & (0.98 to 1.05$)$ & 0.190 \\
\hline Clerical and administrative workers & 1.06 & (1.02 to 1.11$)$ & $<0.001$ & 1.09 & (1.04 to 1.13$)$ & $<0.001$ \\
\hline Sales workers & 1.03 & (0.98 to 1.09$)$ & 0.082 & 1.05 & (1.00 to 1.10$)$ & 0.017 \\
\hline Machinery operators and drivers & 1.01 & (0.97 to 1.04$)$ & 0.671 & 1.01 & (0.98 to 1.04$)$ & 0.380 \\
\hline \multicolumn{7}{|c|}{ Injury/illness (reference: physical injuries, excluding fractures) } \\
\hline Fractures & 1.03 & (1.00 to 1.06$)$ & 0.010 & 1.01 & (0.98 to 1.04$)$ & 0.490 \\
\hline Mental health & 0.61 & (0.59 to 0.64$)$ & $<0.001$ & 0.63 & (0.61 to 0.65$)$ & $<0.001$ \\
\hline Other diseases & 1.35 & (1.30 to 1.40$)$ & $<0.001$ & 1.35 & (1.30 to 1.40$)$ & $<0.001$ \\
\hline
\end{tabular}

Model 1 includes all predictors excluding jurisdiction, while model 2 includes jurisdiction. 


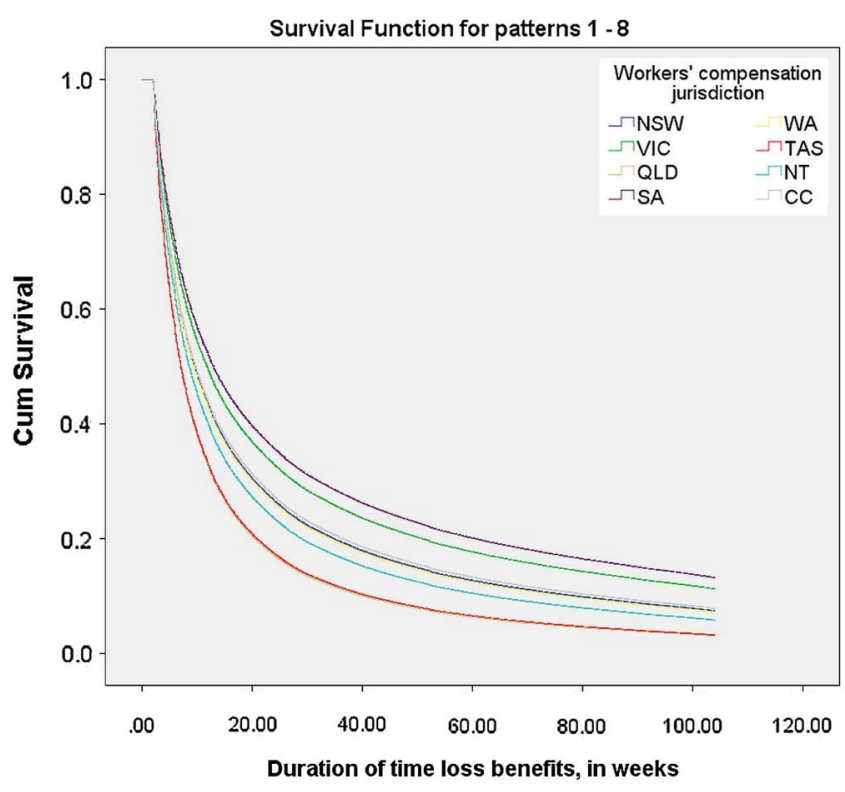

Figure 1 Adjusted survival plots for duration of time loss (weeks) by jurisdiction.

The direction and significance of most findings remain the same, though there were a few notable differences, particularly within industry and occupation variables. Further, there was a change in the direction of association between part-time/full-time hours, where full-time hours switched from being associated with longer time-loss duration in complete case analyses (model excluding jurisdiction only) to shorter time loss in multiple imputation analysis (both models). Additionally, the jurisdiction of Comcare was significantly associated with longer time-loss durations in the multiple imputation analyses but not in the complete case analysis.

It is unclear why these last two associations would change in the multiple imputation model. Missingness did not differ substantially between part-time (14.8\%) and full-time workers $(13.5 \%)$, nor did Comcare have a high proportion of missing $(1.1 \%)$. For the latter, the difference may be attributable to imputations within New South Wales, the comparator, which was missing $22.8 \%$ of its advantage/disadvantage or remoteness variables, compared with $13.7 \%$ across the data set.

\section{DISCUSSION}

This study of over 90000 injured Australian workers presents evidence that the state or territory in which a workrelated compensation claim is made has a substantial and independent impact on duration of work disability as measured by the compensated time away from work. This effect persists even after accounting for demographic, socioeconomic, employment and injury-related factors known to affect duration of time loss.

Descriptive analysis and data visualisation using survival curves illustrate the substantial variation in duration between Australian states and territories. In Queensland, as few as $1 \%$ of injured workers continue to receive income benefits after 104 weeks postinjury, while the equivalent figure in Victoria is $16 \%$. This variation was evident despite excluding cases of 'minor' injury resulting in $<2$ weeks of time loss from all jurisdictions.

Engagement in injury compensation systems has been associated with slower recovery and RTW ${ }^{32}$ including in Australian injury compensation jurisdictions. ${ }^{33}$ Despite this evidence, many studies of people with compensable injury fail to report even the most basic aspects of the compensation system in the jurisdiction from which the study population was derived. ${ }^{9}$ There is emerging literature on the impact of individual compensation system policy settings on injury outcomes. For example, level of compensation benefits has been positively associated with claim incidence rates and time-loss duration. ${ }^{34} 35$ Some studies have also examined the impact of waiting/ excess periods on workers' compensation outcomes, with waiting periods having a negative association with time away from work. ${ }^{34}$ One study examined the impact of workers' compensation policies on RTW outcomes using a comparative, cross-jurisdictional paradigm in six countries. ${ }^{17}$ More recently, a US study identified that waiting periods for wage replacement, limiting initial choice of treating provider and limitations on switching treating medical provider were independently associated with duration of disability in workers with lower back pain. ${ }^{18}$ With these exceptions, there is very little comparative evidence of the relative effectiveness of different approaches to public insurance for work-related injury.

The current study adds to this evidence base. The findings suggest that, even after accounting for worker, workplace and system characteristics that affect duration of work disability, jurisdictional-level factors are significantly associated with duration. Combined with this previous literature, this finding suggests that the design and management of public insurance schemes for injury compensation have a substantial effect on duration of work disability for injured workers receiving income replacement benefits. Unlike some factors affecting claim duration such as SES or injury type, policy and practice are highly modifiable. Prior research has demonstrated that modifications to compensation scheme management practices such as claims handling can have a positive impact on outcomes in Australian injury compensation settings. ${ }^{36}$ Internationally, changes to the macrolevel design of injury compensation systems have produced substantial improvements in health outcomes. ${ }^{35}$ The present findings suggest that similar changes to scheme design and management have the potential to improve outcomes for injured workers in Australian states and territories.

While this study was not designed to identify the impact of specific policy settings, there are some significant differences between jurisdictions that may be contributing to the observed effect, and that will be the subject of future analyses. One major difference is the 
claim waiting period. In two states (Victoria and South Australia), the employer is responsible for the first 10 days of income replacement postinjury, whereas this period is 0 or 1 day in the other states and territories. Combined with policies that provide an additional period of time for claim reporting to a workers' compensation insurer (eg, a further 10 days in Victoria), this policy may interfere with the ability for early intervention postinjury. Some states that have shorter durations in this study have developed work practices that encourage early reporting. For example, in Queensland, there is a financial incentive for general practitioners to report work-related injury claims to the state's workers' compensation insurer. The Australian workers' compensation systems provide access to medical care largely using a 'worker choice' approach, where the injured worker is able to access the provider of their choice through either the public or private healthcare system. This is quite different from the approach reported by Shraim et $a l^{18}$ who identified that policies that limit initial choice of provider and restrict movement between providers had a substantial impact on duration of work disability. This same effect is unlikely to be observed in the Australian setting.

Study strengths include the large data set encompassing the eight major workers' compensation jurisdictions in Australia. The variables within the data set permitted regression analyses that controlled for many covariates known to influence RTW outcomes, enabling the isolation of the impact of jurisdiction on outcome. Limitations include the use of administrative payment data (compensated time loss) as the primary outcome metric. Compensated time loss generally underestimates the amount of time an injured worker is away from work. ${ }^{37}$ Further, income benefit cessation does not necessarily reflect RTW, but in some workers, it may indicate retirement, return to education or other outcomes. The data set reports only the primary injury and thus does not enable analyses of the impact of comorbid conditions or other conditions developing secondary to the primary work-related condition. Research suggests that some injured workers develop mental health conditions during compensation processes, ${ }^{38}$ but it was not possible to examine this. Globally, there is a diversity of approaches to compensation for time off work after work-related conditions, and these findings may not be generalisable to other systems or settings.

The report also demonstrates that it is feasible to conduct comparative studies in Australian workers' compensation systems using existing administrative data sets. The associations between regression covariates and timeloss durations replicate findings of prior research, providing confidence in the study methodology. Such associations include longer time-loss durations for female and older claimants, ${ }^{11}$ manual labour occupations ${ }^{39}$ and mental health claims. ${ }^{13}$

In Australia, commonwealth, state and territory governments have chosen workers' compensation systems as the primary means via which they seek to encourage RTW of injured workers. Variations on this approach are in place in most other industrialised and many developing nations. Workers' compensation policy is composed of myriad and complex rules, each of which may improve or worsen RTW outcomes for injured workers. This study provides evidence that in Australia, the jurisdiction in which a workers' compensation claim is made has a significant impact on duration of time off work, independent of other factors. While this study does not identify specific policies and practices that improve or limit RTW, the findings justify further research in this area.

Twitter Follow Alex Collie at @axcollie

Acknowledgements The authors would like to acknowledge the contribution of state and territory workers' compensation agencies for data provision, and Shannon Gray for assistance with preparation of the manuscript for publication.

\section{Collaborators Shannon Gray.}

Contributors AC conceived the study and drafted the manuscript. TJL conducted analyses and contributed to manuscript preparation. BH-M, CM and JT contributed to analyses and manuscript preparation. All authors approved the final manuscript.

Funding This study was supported by a grant from Safe Work Australia and WorkSafe Victoria.

Competing interests $\mathrm{AC}$, TJL, JT and $\mathrm{BH}-\mathrm{M}$ receive salary support via a grant from WorkSafe Victoria and the Transport Accident Commission. Both are state government regulatory agencies in the state of Victoria, Australia.

Ethics approval Monash University Human Research Ethics Committee.

Provenance and peer review Not commissioned; externally peer reviewed.

Data sharing statement No additional data are available.

Open Access This is an Open Access article distributed in accordance with the Creative Commons Attribution Non Commercial (CC BY-NC 4.0) license, which permits others to distribute, remix, adapt, build upon this work noncommercially, and license their derivative works on different terms, provided the original work is properly cited and the use is non-commercial. See: http:// creativecommons.org/licenses/by-nc/4.0/

\section{REFERENCES}

1. Haagsma JA, Graetz N, Bolliger I, et al. The global burden of injury: incidence, mortality, disability-adjusted life years and time trends from the Global Burden of Disease study 2013. Inj Prev 2016;22:3-18.

2. International Labour Organization. Safety and Health at Work: $A$ Vision for Sustainable Prevention: XX World Congress on Safety and Health at Work 2014: Global Forum for Prevention, 24-27 August 2014, Frankfurt, Germany. Geneva: International Labour Office, 2014.

3. Bacikova-Sleskova M, Benka J, Orosova O. Parental employment status and adolescents' health: the role of financial situation, parent-adolescent relationship and adolescents' resilience. Psychol Health 2015;30:400-22.

4. Newnam S, Collie A, Vogel AP, et al. The impacts of injury at the individual, community and societal levels: a systematic meta-review. Public Health 2014;128:587-618.

5. Waddell G, Burton AK. Is work good for your health and well-being? London: Department for Work and Pensions, 2006.

6. Dembe AE. Social inequalities in occupational health and health care for work-related injuries and illnesses. Int $J$ Law Psychiatr 1999;22:567-79.

7. Asfaw AG, Bushnell PT, Ray TK. Relationship of work injury severity to family member hospitalization. Am J Ind Med 2010;53:506-13.

8. Lippel K, Lötters F. Public insurance systems: a comparison of cause-based and disability-based income support systems. In: Loisel 
P, Anema JR, eds. Handbook of work disability. 2nd edn. New York: Springer, 2013:183-202.

9. Clay FJ, Berecki-Gisolf $J$, Collie A. How well do we report on compensation systems in studies of return to work: a systematic review. J Occup Rehabil 2014;24:111-24.

10. Safe Work Australia. Comparison of workers' compensation arrangements in Australia and New Zealand. Canberra: Safe Work Australia, 2015.

11. Berecki-Gisolf J, Clay FJ, Collie A, et al. The impact of aging on work disability and return to work: insights from workers' compensation claim records. J Occup Environ Med 2012;54:318-27.

12. Berecki-Gisolf J, Clay FJ, Collie A, et al. Predictors of sustained return to work after work-related injury or disease: insights from workers' compensation claims records. J Occup Rehabil 2012;22:283-91.

13. Smith PM, Black O, Keegel T, et al. Are the predictors of work absence following a work-related injury similar for musculoskeletal and mental health claims? J Occup Rehabil 2014;24:79-88.

14. MacEachen E, Clarke J, Franche RL, et al. Systematic review of the qualitative literature on return to work after injury. Scand $J$ Work Environ Health 2006;32:257-69.

15. Brouwer S, Amick BC, III, Lee $\mathrm{H}$, et al. The predictive validity of the return-to-work self-efficacy scale for return-to-work outcomes in claimants with musculoskeletal disorders. J Occup Rehabil 2015;25:725-32.

16. Adams H, Ellis T, Stanish WD, et al. Psychosocial factors related to return to work following rehabilitation of whiplash injuries. J Occup Rehabil 2007;17:305-15.

17. Anema JR, Schellart A, Loisel P, et al. Can cross country differences in Return-to-Work after chronic occupation back pain be explained? An exploratory analysis on disability policies in a six country cohort study. J Occup Rehabil 2009;19:419-26.

18. Shraim M, Cifuentes M, Willetts JL, et al. Length of disability and medical costs in low back pain: do state workers' compensation policies make a difference? J Occup Environ Med 2015;57:1275-83.

19. Australian Bureau of Statistics. 6324.0-Work-related injuries, Australia, JUL TO JUN 2014. Canberra: Australian Bureau of Statistics, 2014.

20. Safe Work Australia. The cost of work-related injury and illness for Australian employers, workers and the community: 2008-09. Canberra: Safe Work Australia, 2012.

21. Lippel K. Preserving workers' dignity in workers' compensation systems: an international perspective. Am J Ind Med 2012;55:519-36.

22. Safe Work Australia. National Data Set for Compensation-based Statistics, Third Edition. Canberra: Safe Work Australia, 2004.

23. Krause N, Dasinger LK, Deegan LJ, et al. Alternative approaches fo measuring duration of work disability after low back injury based on administrative workers' compensation data. Am J Ind Med 1999;35:604-18.
24. Prang $\mathrm{KH}$, Bohensky $\mathrm{M}$, Smith $\mathrm{P}$, et al. Return to work outcomes for workers with mental health conditions: a retrospective cohort study. Injury 2016;47:257-65.

25. Australian Bureau of Statistics. Australian and New Zealand standard classification of occupations, 2013, Version 1.2. Canberra: Australian Bureau of Statistics, 2013.

26. Australian Bureau of Statistics. 1292.0-Australian and New Zealand Standard Industrial Classification (ANZSIC), 2006 (Revision 2.0). Canberra: Australian Bureau of Statistics, 2013.

27. Australian Safety and Compensation Council. Type of occurrence classification system 3rd Edition, revision 1. Canberra: Commonwealth of Australia, 2008.

28. Department of Health and Aged Care. Measuring Remoteness: Accessibility/Remoteness Index of Australia (ARIA) Revised Edition. Occasional Papers: New Series Number 14. Canberra: Department of Health and Aged Care, 2001.

29. Australian Bureau of Statistics. 2006 RA from 2006 POA Correspondence. Australian Standard Geographical Classification (ASGC) Remoteness Area Correspondences, 2006. Canberra, 2011.

30. Australian Bureau of Statistics. Postal Area, Indexes, SEIFA 2011. Census of Population and Housing: Socio-Economic Indexes for Areas (SEIFA), Australia, 2011. Canberra, 2013.

31. Safe Work Australia. Comparative performance monitoring report. 17th edn. Canberra: Safe Work Australia, 2015.

32. Harris I, Mulford J, Solomon M, et al. Association between compensation status and outcome after surgery: a meta-analysis. JAMA 2005;293:1644-52.

33. Gabbe BJ, Cameron PA, Williamson OD, et al. The relationship between compensable status and long-term patient outcomes following orthopaedic trauma. Med J Aust 2007;187:14-7.

34. Butler R. Economic determinants of workers' compensation trends. J Risk Insur 1994;61:383-401.

35. Cassidy JD, Carroll LJ, Côté P, et al. Effect of eliminating compensation for pain and suffering on the outcome of insurance claims for whiplash injury. N Engl J Med 2000;342:1179-86.

36. Schaafsma F, De Wolf A, Kayaian A, et al. Changing insurance company claims handling processes improves some outcomes for people injured in road traffic crashes. BMC Public Health 2012;12:36. http://www.biomedcentral.com/1471-2458/12/36

37. Dasinger LK, Krause N, Deegan LJ, et al. Duration of work disability after low back injury: a comparison of administrative and self-reported outcomes. Am J Ind Med 1999;35:619-31.

38. Kilgour E, Kosny A, McKenzie D, et al. Interactions between injured workers and insurers in workers' compensation systems: a systematic review of qualitative research literature. J Occup Rehabil 2015;25:160-81.

39. Lilley R, Davie G, Ameratunga S, et al. Factors predicting work status 3 months after injury: results from the prospective outcomes of injury study. BMJ Open 2012;2:e000400. 